\title{
REVISITACIÓN SOBRE ATTILIO ROSSI Y LA CRÍTICA MILITANTE EN SUR: BUENOS AIRES 1936-1938
}

\section{MARIA VICTORIA STREPPONE UNIVERSIDAD CA' FOSCARI DE VENECIA}

\begin{abstract}
RESUMEN: Este trabajo analiza la presencia del artista italiano Attilio Rossi como crítico de arte entre 1936 y 1938 en la revista argentina Sur. Se indaga el modo en el cual sus artículos contribuyeron en la profesionalización de la figura del crítico especializado y marcaron el inicio de la crítica militante en la ciudad porteña. Basándose en el análisis de fuentes interdisciplinarias, se considera a Rossi como parte de una implacable diáspora creativa entre Argentina e Italia y se aborda la cuestión de la identidad cultural reflejada en el arte entrelazando a través de relaciones significativas los dos lados del océano.
\end{abstract}

PALABRAS CLAVE: Attilio Rossi, Sur, arte, crítica, Argentina.

\section{REVISITING ATTILIO ROSSI AND THE MILITANT CRITICISM IN SUR: BUENOS AIRES 1936-1938}

\begin{abstract}
This paper analyzes the figure of the Italian artist Attilio Rossi as an art critic between 1936 and 1938 in the Argentinian magazine Sur. It investigates how his articles contributed to the professionalization of the figure of the specialized critic and marked the beginning of militant criticism in the city of Buenos Aires. Based on the analysis from interdisciplinary sources, Rossi is considered part of a relentless creative diaspora between Argentina and Italy and addresses the issue of cultural identity reflected in art by interweaving significant relationships between the two countries on the opposite sides of the ocean.
\end{abstract}

KEYWORDS: Attilio Rossi, Sur, art, criticism, Argentina. 


\section{Introducción}

En septiembre del 2018 El Instituto Cervantes inauguró la exposición “Cómo se imprime un libro. Grafistas e impresores en Buenos Aires 1936-1950”, una muestra retrospectiva que se concentra en la "época de oro" "de la actividad editorial en Argentina y que resalta la figura de Attilio Rossi, desde el punto de vista creativo, en lo que respecta a la "construcción" de los libros². Si bien dicho evento permite conocer una faceta importante del trabajo de Rossi (Albairate-Milán, 1909-1994) la fortuna crítica del artista italiano por momentos no se percibe en la totalidad de su riqueza ni en la complejidad de su obra, no solo como diseñador gráfico, sino también como pintor e intelectual, crítico de arte, curador de exposiciones y mediador cultural, potenciando las relaciones entre distintos países y artistas. De hecho, intervino personalmente para hacer llegar a Italia el Guernica a la muestra dedicada a Picasso en el Salone delle Cariatidi de Milán en $1953^{3}$.

El historiador de arte Luciano Caramel en colaboración con Pablo Rossi, hijo del artista, reconstruyen una parte de la actividad laboral de Rossi a partir de sus primeras experiencias en el ámbito de la decoración y sucesivamente en el ambiente tipográfico a partir de $1922^{4}$. Estas experiencias permitirán a Rossi asistir a la Accademia di Brera así como a la Scuola d'Arte applicata del Castello Sforzesco, desde donde se traslada a Milán hacia 1926 para ampliar sus conocimientos sobre tipografía. Más tarde colabora como proyectista gráfico en el Istituto Vanzetti e Vanoletti y termina sus estudios en la Scuola del Libro, especializándose en compaginación y diseño gráfico. El clima milanés es culturalmente muy activo; no casualmente es la cuna de la arquitectura racionalista y testimonio del inicio del Novecento Italiano ${ }^{5}$, sino que también es permeable a las iniciativas de las vanguardias artísticas internacionales, con las cuales Rossi y un grupo de amigos estudiantes se identifican estéticamente. María Eugenia Costa comenta con detalle los aspectos de este período en el

\footnotetext{
${ }^{1}$ SÁNCHEZ VIGIL, Juan Miguel y OLIVERA ZALDUA, María: "La Colección Austral: 75 años de cultura en el bolsillo (1937-2012)", Palabra Clave (La Plata), vol. 1, n. 2 (2012), pp. 29-47. Disponible en http://www.palabraclave.fahce.unlp.edu.ar.

2 Véase el catálogo de la muestra en el Instituto Cervantes: Cómo se imprime un libro. Grafistas e impresores en Buenos Aires 1936-1950, GARCÍA MONTERO, Luis (Coord.), Madrid, Talleres de Sgraf, 2018.

3 Véase ROSSI, Pablo: 2012, Alla scoperta delle lettere perdute di Attilio Rossi, Milán, Ed. Privata, 2012.

${ }^{4}$ CARAMEL, Luciano y ROSSI, Pablo: “Regesto”, L.C. (Coord.), Attilio Rossi. Le opere 1933-1994, Milán, Giunti, 1996, pp. 201-216.

${ }^{5}$ Los artistas del Novecento Italiano (o Novecento), reunidos en torno a la crítica de arte Margherita Sarfatti y el moderno galerista Lino Pesaro, tuvieron su primera exposición en 1926. Si bien en parte el grupo del Novecento buscó alejarse del academicismo, coinciden, en contraposición con las vanguardias, en la necesidad de recuperar los valores del arte de la antigüedad clásica, es decir la pureza de las formas y la armonía en la composición.
} 
que Rossi aborda el ambiente editorial y consolida su estilo de diseño ${ }^{6}$. A partir de 1932 y en compañía de Carlo Dradi funda, e inicialmente dirige, la revista Campo Gráfico que, si bien dejó de publicarse en 1939, marcó el comienzo del proceso de modernización de las artes gráficas en Italia. Campo Gráfico posee una estética innovadora ${ }^{8}$ y afronta no solo las cuestiones prácticas y operativas de las artes gráficas como oficio, sino que ofrece una estética compositiva inédita al proponer fotomontajes y nuevos caracteres tipográficos. Rossi ya cuenta con una amplia formación en este ámbito y se ocupa, con profunda sensibilidad crítica, de cuestiones teóricas que evidencian sus inquietudes intelectuales.

En 1935, Rossi deja Italia debido al clima político del fascismo y se dirige a Buenos Aires con "un contrato de trabajo con el tipográfico argentino de origen italiano Gino Fogli"”. A su vez Cesare Zavattini, escenógrafo y guionista cinematográfico asociado al neorrealismo italiano, le procura el nombre del escritor argentino Eduardo Mallea. Poco después de llegar a la ciudad porteña y siguiendo la sugerencia de Zavattini, Rossi se encuentra con Mallea quien en breve le propone seguir la sección "Crítica de arte" de la revista argentina Sur que estuvo en circulación entre 1931 y 1992. La publicación creada y dirigida por la intelectual Victoria Ocampo (Buenos Aires, 1890-1977), se propuso re-pensar el canon estético de la literatura y del arte en general, desde la música a la pintura, incluyendo la arquitectura y el cine con una innovadora forma "crítica". A través de una mirada orientada hacia las propuestas europeas, Sur afronta argumentos multidisciplinarios y multiculturales, con un comité editorial heterogéneo y vanguardista, cuyos nombres hoy resuenan a nivel internacional debido a sus ideas sin precedentes para la época.

Basado en una extensa investigación de archivos y en el estudio de la bibliografía sobre el tema, este trabajo considera la presencia de Attilio Rossi en la revista Sur, desde una perspectiva que lo coloca, durante su residencia en Buenos Aires, en el centro de una serie de relaciones entre artistas e intelectuales internacionales del calibre de Jorge Luis Borges, Emilio Pettorutti, Lucio Fontana o Rafael Alberti. Dichas relaciones, darán lugar a eventos únicos, como la primera exposición de arte abstracto en la Gallería Moody ${ }^{10}$, el trabajo en la

\footnotetext{
${ }^{6}$ COSTA, María Eugenia: "La trayectoria de Attilio Rossi en los albores del diseño editorial moderno en Argentina (1935-1950)”, Caiana, n. 12 (Primer semestre 2018), pp. 156-172.

Disponible en http:/ / caiana.caia.org.ar/template/caiana.php ?pag=articles/article_2.php\&obj=316\&vol=12

7 MAINETTI, Giulia: “L’Esperienza di Campo Grafico”, L.C. (Coord.), Attilio Rossi. Le opere 1933-1994, Milán, Giunti, 1996, pp. 162-164.

8 Véase ROSSI, Pablo: “Attilio Rossi e Campo Grafico una lez̧ione di modernita”, Milán, Ed. Privata, 2013.

9 ROSSI, Pablo: “Attilio Rossi, la pasión por el libro”, L.G.M. (Coord.), Cómo se imprime un libro. Grafistas e impresores en Buenos Aires 1936-1950, Madrid, Talleres de Sgraf, 2018, pp. 69-78.

${ }^{10}$ ROSSI, Attilio: "Primera exposición de dibujos y grabados abstractos en la Galería Moody", Sur, n. 28 (enero, 1937), pp. 93-98.
} 
IX Triennale di Milano ${ }^{11}$ o la ya mencionada "mediación" para hacer llegar a Italia el Guernica. La progresiva incorporación de Rossi como crítico de arte acentuó en el panorama porteño, un cambio de rumbo en las artes plásticas y visuales, no solo desde su creación material sino también desde el modo con el cual se re-propone el arte como experiencia estética. La crítica de arte de Rossi es provocativa y plantea un nuevo modo de acercarse al panorama creativo internacional, alejándose del sentimentalismo local hacia las nociones del academicismo, por lo tanto, un primer flujo de información, conocimiento y tendencias ve a Rossi como protagonista en la regulación de los mecanismos que acercan el panorama creativo argentino a la crítica militante, es decir una actitud que implica la participación activa en la vida cultural de su tiempo.

Es verosímil pensar que cuando Rossi desde su rúbrica se expresa en modo analítico y sin falsos ceremoniales sobre el ambiente artístico argentino, o bien respecto a los críticos ya establecidos, el sistema de muestras y los artistas, significó la pérdida de una posición acomodada ante la élite cultural local que se sintió contrapuesta a las experiencias estéticas de los dos países. El epílogo negativo del asunto, es lo que permite a Rossi construirse una identidad propia y distintiva a través del arte; justamente éste es el punto donde el material recuperado de la literatura artística testimonia una red de relaciones (e intenciones) en las que, durante su exilio, Rossi establece contactos significativos entre los dos lados del océano en el intento de vincular los mejores artistas, escritores y profesionales de su tiempo en un proyecto que colaborase con la renovación estética, histórica y crítica.

La necesidad de actualizar la contribución teórica de Rossi, se focaliza en reconstruir la trayectoria biográfica e intelectual que éste conduce en torno a Sur. La continuidad temporal que caracterizó la revista, publicada durante más de 4 décadas, es esencial en el debate sobre la formación del gusto del país sudamericano. Dicho debate, debe entenderse teniendo en cuenta dos circunstancias fundamentales: por una parte, el proceso de inmigración que implicó un lento desplazamiento (y resistencia) de los convencionalismos locales coincide con la búsqueda de "modernización" de una sociedad que, a partir de la propia cultura de "mezcla", trata de consolidar su identidad artística. Por otra, es el momento en el cual la crítica de arte y otras formas de "crítica" en Argentina, tienden a emanciparse de la visión que se desprendía de la literatura y que, en el intento de auto-renovación, se planteaban la necesidad (o no) de continuidad con el arte europeo.

\footnotetext{
${ }^{11}$ Se trata de una instalación conjunta e interdisciplinaria. El evento es el resultado de un proyecto para el atrio de la Triennale en el cual participan el arquitecto Luciano Baldessari y el artista Lucio Fontana. Attilio Rossi, crea una "obra-pavimento" que da unidad y continuidad al recorrido en el espacio.
} 


\section{El periplo del arte en Sur}

A principios de los años veinte del siglo pasado, muchos intelectuales argentinos después de un período sabático en Europa ${ }^{12}$ (fundamentalmente en España, Francia e Italia), regresan al país envueltos por el clima innovador y revolucionario de las vanguardias artísticas. A partir de este momento, en una Buenos Aires que se piensa a sí misma como una ciudad cosmopolita, comenzaron a consolidarse algunos grupos formados principalmente por $\operatorname{artistas}^{13}$ y escritores ${ }^{14}$ en torno a distintas revistas, las cuales se convirtieron en un medio importante para reflejar los acontecimientos culturales. Cabe también señalar que el concepto de "profesionalización" de los escritores era bastante reciente y que, con el desarrollo de una industria editorial, el cuestionamiento del devenir cultural encontró un espacio que le permitió confrontarse con los convencionalismos heredados de la tradición académica europea, ya obsoleta en el viejo continente. Comprender este momento de transición, permite intuir la complejidad del ambiente en el cual se desarrolla el diálogo entre Rossi y la ciudad idealmente "cosmopolita". Esta percepción determina una renovación constante del contexto de los intelectuales en el intento de trasladar las imágenes de las grandes metrópolis europeas a Buenos Aires. Sin embargo, en una especie de convulsión hacia la modernidad, dichas imágenes tienden a modificarse cuando pasan el Océano; emergen grandes contradicciones y no es simple hacerlas coincidir en un modelo unívoco, en el caso de que se aceptase abandonar el legado académico.

"Tu trovi che ho fatto male, ma dato che i proponenti mi son parsi all'oscuro del tutto o quasi di quel che è lo stato dell'arte italiana, dato che ho saputo il pubblico di laggiù piuttosto cafone o snobistico ammiratore di blagues francesi, dato che non era possibile "rappresentare l'arte italiana" (come volevamo) con una scelta e strettissima esposizione di gruppo, dato che finalmente in Italia è impossibile concludere qualsiasi cosa fra artisti, per l'idiota anarchismo e confusionismo e suscetti-vismo che regna nella nostra classe (...) ho ritenuto che il meno peggio era rimetter tutto nelle solite mani della Sarfatti”. ${ }^{15}$

\footnotetext{
${ }^{12}$ En el ámbito de la cultura argentina, es el período durante el cual el país experimenta significativos cambios sociales y económicos, al mismo tiempo que se instaura una involución política. A partir de los beneficios económicos del 1910 y más que nunca entre los años 20 y finales los años 30, muchos argentinos que es tudiaban o viajaban a Europa, tenían la intención de traer tendencias y estímulos de las metrópolis europeas a Buenos Aires, con el objetivo de consolidar una "modernidad periférica" (como lo llama Beatriz Sarlo). Véase SARLO, Beatriz: Una modernità periferica. Buenos Aires 1920-1930, Macerata, Quodlibet Studio, 2005.

${ }^{13}$ En París, se encuentra un grupo de artistas plásticos argentinos: Aquiles Badi, Horacio Butler y Pablo Curatella Manes, amigo del pintor Emilio Pettoruti. Éste último, junto con Antonio Sibilino, habían elegido Italia para comenzar su formación en pintura y escultura residiendo en Florencia y Turín, respectivamente. Un gran grupo de argentinos se dispersó por toda Europa y, junto con Xul Solar, Juan del Prete, Antonio Berni y otras personalidades, forman parte de la peregrinación argentina por las raíces de cultura europea.

${ }^{14}$ En el ambiente literario, Jorge Luis Borges y Ricardo Güiraldes, se habían quedado y estudiado en Europa, divididos entre Ginebra y París respectivamente. Al mismo tiempo, los arquitectos Alberto Prebisch y Ernesto Vautier viajaron por el viejo continente durante dos años reconstruyendo las fuentes europeas.

15 ["Encuentras que hice mal, pero como los proponentes me parecieron desconocer por completo o casi por
} 
Este testimonio es parte de los preliminares de lo que será la famosa muestra de artes plásticas del "Novecento Italiano" presentada en Buenos Aires (y más tarde en Rosario) en septiembre de $1930^{16}$ y organizada por Margherita Sarfatti, prestigiosa crítica de arte italiana cercana al fascismo. Lo que llama la atención del fragmento citado es la profunda reflexión a la que se fuerza el sentimiento crítico: toda la primera parte del texto, de hecho, trata de justificar la percepción del clima cultural predominante en Buenos Aires además de la incomprensión entre los mismos artistas italianos. Según Ardengo Soffici, en su carta a Carlo Carrà (uno de los participantes a la muestra) la confusión de una ciudad de gustos snobs y prácticamente al margen de la sensibilidad artística contemporánea, con una mentalidad anticuada (determinada por los modismos franceses), es lo que condiciona la propuesta misma de la muestra. Las palabras de Soffici, que coinciden con el pensamiento de muchos de los intelectuales argentinos, testimonian los evidentes límites estético-culturales que afectaban a la Argentina en aquellos años. Consecuentemente en Buenos Aires, los grupos de artistas y de escritores que comparten una actitud innovadora se consolidan y uno en particular, en torno a la revista $\operatorname{sur}^{17}$ y a su fundadora, Victoria Ocampo que, conjuntamente con Mallea (escritor y colaborador), proyectan en la figura de Rossi varias de sus expectativas respecto a la nueva estética del arte, lo cual justifica formalmente su presencia en la revista.

"Il gruppo concentrato attorno a Sur si propone di promuovere il rinnovo estetico difendendo la specificità dell'arte, e malgrado il rifiuto del dibattito politico concreto, non evita di prendere posizione sui grandi conflitti politici. In formato libro Sur verrà pubblicata regolarmente fino a $1970 " .18$

completo cuál es el estado del arte italiano, dado que he sabido que el público de allí es bastante grosero o esnob admirador de las blasfemias francesas, ya que no era posible "representar el arte italiano" (como queríamos) con una exposición colectiva escogida y muy apretada, ya que finalmente en Italia es imposible concluir nada entre los artistas, debido al anarquismo idiota y la confusión y el susceptivismo que reina en nuestra clase (...) he considerado que lo menos malo era poner todo de nuevo en las habituales manos de Sarfatti”.] CARRÀ, Carlo y SOFFICI, Ardengo: Lettere 1913-1929. Carlo Carrà - Ardengo Soffici, Feltrinelli, 1983, pp. 191. [N.d.A]

${ }^{16}$ Entre septiembre y octubre de 1930 en el espacio de la Asociación Amigos del Arte se exhibió la muestra itinerante de arte italiano, conocida como "Novecento Italiano", organizada por prestigiosos miembros de la comunidad ítalo-argentina.

${ }^{17}$ Si bien el último número de la revista fue publicado en 1992, Victoria Ocampo declara en 1974 (Testimonios. Novena serie, p. 210) que Sur continuará en funcionar en modo estable solo como editorial, especificando que luego de 326 números publicados, la revista tendrá una cadencia ocasional. Ocampo sin embargo continúa en escribir y publicar sus Testimonios (obra que recoge los ensayos y algunas de sus cartas) hasta 1977. En 1979, la directora de Sur fallece, con lo cual se puede considerar que hasta ese momento la revista mantiene los presupuestos iniciales de su fundadora.

18 ["El grupo concentrado en torno a Sur tiene como objetivo promover la renovación estética defendiendo la especificidad del arte y, a pesar de rechazar el debate político concreto, no evita tomar posición sobre los grandes conflictos políticos. En formato de libro Sur se publicará regularmente hasta 1970".] PACHECO, Marcelo y CRISPOLTI, Enrico: Arte Astratta Argentina, Bergamo-Buenos Aires, Gamec-Proa, 2002, p.199. [N.d.A] 
Dada la longevidad de Ocampo así como del proyecto editorial Sur, ambos son considerados una parte determinante de la cultura argentina, al punto que en 1986 John King, profesor de la Universidad de Warwick, define Sur como "la principal revista cultural de la Argentina en el siglo XX" ${ }^{19}$.

Los temas tratados en Sur a partir de 1931 y sucesivamente en la editorial homónima (siguiendo el consejo de Ortega y Gasset y emulando en este aspecto la Revista de Occidente) serán ensayos, notas y artículos que buscan renovar el canon estético argentino a partir de una mirada ecléctica. El proyecto Sur implica un discurso multidisciplinario y se dedica a promover en modo casi obstinado, la literatura y el arte contemporáneo tanto europeo como local. Amiga de Ortega, Ocampo y sus colaboradores intuyen en la contemporaneidad de las artes la oportunidad de generar nuevas posibilidades expresivas para un país joven como Argentina que busca reinventarse. La emancipación del gusto académico heredado de Europa es un puzzle en el cual desde la crítica de arte y de otras disciplinas, se le proponen al lector y al público nuevos paradigmas de composición. Esta maniobra no quita que para la directora de Sur la relación con la tradición fuera fundamental; asumir la carencia de un ligamen histórico, implica reconocer la distancia implícita entre las metrópolis culturales europeas y Buenos Aires. Para Ocampo, admitir esta ausencia es lo que le permite relacionarse con el arte desde una nueva perspectiva ${ }^{20}$ y la presencia de Rossi lo confirma. Su presencia trata de definir las nuevas experiencias que se pueden establecer con el arte a partir de una propuesta alternativa de "modernidad" mediada por Sur.

En función de todo lo anterior, los distintos grupos que compartían una actitud de renovación hacia la cultura, se reúnen alrededor de revistas como Prisma (1921) o Proa y Martín Fierro (1924) y una década más tarde, en proyectos editoriales como Sur (1931) o la revista Contra que dirigió Raúl González Tuñón (1933) ${ }^{21}$. Todas estas iniciativas no definen una trayectoria regular, pero están vinculadas entre sí por la búsqueda del espíritu modernizante como impulso totalizador. Sur, al ser financiada por Ocampo, no solo se

\footnotetext{
${ }^{19}$ KING, John.: Sur: A Study of the Argentine Literary Journal and its Role in the Development of a Culture, 1931-1970, New York, Cambridge University Press, 1986, p. 202.

${ }^{20}$ Se debe tener en cuenta que, a diferencia de otros países de Latinoamérica, Argentina se caracteriza no solo por ser una sociedad multiétnica y multilingüe, sino también por tener una clase "culta" dominante que cree no poder prescindir de los lineamientos estéticos europeos. Esto conlleva a una constante dependencia del viejo continente. Contemporáneamente, se desarrolla la fuerte voluntad de construir una identidad estética propia, lo cual genera cierta tensión al tratar de recuperar en la heterogeneidad cultural una potencialidad. En este contexto, poco a poco se hace necesario identificar los elementos locales capaces de unificar las distintas experiencias extranjeras en un lenguaje estético común y en grado de ofrecer una dimensión en la cual se pueda vincular a la experiencia europea, las nuevas vivencias: construir propuestas estéticas compartidas se puede transformar en el punto de partida hacia la renovación de la cultura argentina en cuanto cultura de mezcla.

${ }^{21}$ Un breve análisis sobre las revistas precedentes a Sur, se puede encontrar en: SARLO, Beatriz: op. cit.
} 
destaca por su impactante longevidad sino también por mantener una tendencia unívoca, que sigue el gusto de su fundadora, reconstruible en la heterogeneidad de las iniciativas llevadas a cabo $^{22}$ y en el espíritu de sus colaboradores. Entre los más relevantes figuran Jorge Luis Borges y Eduardo Mallea, pero también Attilio Rossi, portavoz de eclecticismo y modernidad, tanto desde su formación como desde su propuesta crítica y artística ${ }^{23}$.

Cuando en 1936 Rossi toma a su cargo la sección de crítica de arte, Sur se transforma de trimestral en mensual. Como diseñador gráfico, sugiere para la portada de cada número un color alusivo que siga las estaciones; primavera, verano con colores cálidos y una paleta fría para el otoño e invierno ${ }^{24}$. La crítica de arte, que se publica en la sección "Notas", inicia a tener continuidad de autores y temas; se ocupan de cine tanto Borges como Ocampo, alternándose entre otros colaboradores.

En el plano práctico, la heterogeneidad de temas y autores que se publican hacen funcionar la revista como una infraestructura para la experimentación, difundiendo por primera vez artículos y teorías de personalidades cuyas ideas cambiarán la propia disciplina. Es suficiente pensar en los textos de Walter Gropius, Sergej Ėjenštejn, Le Corbusier o Virginia Woolf. En efecto, Sur construye su propio ámbito y es pionera en sus contactos transcontinentales y multidisciplinarios porque analiza los problemas de su tiempo desde una perspectiva de modernización integral. La crítica de arte visuales, ahora lleva la impronta Rossi y adquiere no solo periodicidad sino coherencia en el lenguaje que concuerdan los distintos artículos, conjuntamente con otras formas de crítica (que teorizan sobre música o literatura) presentes ya desde el primer número. Sin embargo, es solo a partir de 1935 que se enfatiza una línea estética que establece en pocos números las bases de la crítica militante porteña.

En el plano teórico, los ensayos de Rossi se organizan para despertar el gusto del público y promover exposiciones en las cuales hay una mayor independencia del artista respecto a los cánones académicos. Hacer confrontar al público con las nuevas tendencias expositivas de pintura y de diseño define una estrategia coherente con la internacionalidad de su sección. Rossi, como artista e intelectual extranjero, es ajeno al ambiente literario y al periodismo local, con lo cual establece en el rol del crítico de arte una figura profesional e independiente, capaz de entretener al lector a lo largo de un camino de reflexión personal.

\footnotetext{
${ }^{22}$ Véase OCAMPO, Victoria: Testimonios. Novena serie, Buenos Aires, Editorial Sur, 1970, pp. 205-211.

${ }^{23}$ Respecto a la figura de Attilio Rossi en Sur, véase: SUÁREZ GUERRINI, Florencia: "La crítica de arte argentina en los márgenes de la modernización cultural: Attilio Rossi y la intervención de la revista Sur", s.n., s.l., (2017), pp. 1-12.

Disponible en http://es.scribd.com/doc/52289757/Sur-y-Attilio-Rossi.

${ }^{24}$ ROSSI, Attilio: "Omaggio a Victoria", AA.VV, Testimonios sobre Victoria Ocampo, Buenos Aries, Héctor Basaldúa, 1962, pp. 313-317.
} 


\section{Hacia la conceptualización del arte remanente}

Durante los primeros años en Milán y el período de Campo Grafico, Rossi es sensible a las propuestas del cubismo de Le Corbusier y al funcionalismo estético de la Bauhaus. Respecto a la pintura, Pablo Picasso será una gran influencia para él así como todo el arte abstracto. A lo largo de sus años en Buenos Aires, descubrirá su vocación como pintor motivado por el espíritu multicultural presente en la ciudad porteña. Las experiencias en el extranjero son parte integral de las vivencias de Rossi y producen magníficos resultados que combinan el pasado histórico con la sensibilidad artística ante la novedad de lo cotidiano. Testimonio de esto es el MOMA, (Museum of Modern Art de New York) que conserva un óleo suyo pintado en 1942, Paesaggio di Buenos Aires, como constatación de su vivacidad artística e intelectual que se nutre de la vitalidad cultural porteña. Fruto de la formación inicial como gráfico y de su predisposición hacia la pintura, Rossi se vale del conocimiento de varias prácticas interdisciplinarias cuando interpreta tanto una obra como la organización de una muestra. Es en grado de comprender las reglas del montaje (tanto pictórico como cinematográfico) y llega a percibir la obra en un modo panorámico que luego traduce en palabras. Sin embargo, a pesar de su visión fuertemente innovadora, el estudio de su faceta como crítico de arte ha quedado relegado a un segundo plano frente a su amplia labor pictórica o editorial. No obstante esto, sus ensayos establecen una serie de relaciones entre intelectuales y artistas que permiten sentar las bases de un cuerpo teórico respecto a las artes visuales y su consecuente debate respecto al arte contemporáneo argentino. Como crítico, Rossi percibe en la modernidad un ámbito de análisis privilegiado debido a que sus ritmos son tan rápidos y dinámicos, que no le permiten repetir formas ni recrear complementos excesivos.

En 1936 Sur publica en el número 16 el primer artículo de Rossi, en el cual el autor se propuso defininir la crítica de arte a partir de una posición multidisciplinaria con el texto "Enseñanzas de un film”; reseña cinematográfica de La traviesa molinera. La película dirigida por Harry D'Abbadie D’Arrast y Ricardo Soriano del 1934 es una adaptación del libro “El sombrero de tres picos" de Pedro Antonio de Alarcón. Si bien tanto Borges como Ocampo se habían ocupado de comentar otras películas, principalmente haciendo reseñas, podría llamar la atención que Rossi inaugure la sección de la "crítica de arte" abordando justamente una producción española. Sin embargo, al ocuparse del cine en su primer artículo y considerando que este aún no era del todo considerado como "arte", el texto se transforma en un gesto que permite a Rossi no solo posicionarse como un hombre de cultura 
internacional y profunda sensibilidad, sino que también le permite comenzar a establecer la artisticidad de un elemento que no estaba completamente relacionado con la cultura, sino con el entretenimiento debido a sus cualidades técnicas y a su dimensión industrial como lo enuncia Walter Benjamín ${ }^{25}$. Sin embargo, es importante considerar que la presencia del futurismo italiano y los conocimientos del ambiente tipográfico de donde Rossi proviene, le consienten ver en la tecnología y en el maquinismo, los elementos creativos que convierten una película en "arte del cinematográfico", es decir un arte sensible a los procesos tecnológicos de su tiempo.

En el número 18 de Sur, el segundo artículo de Rossi declara las reglas para una buena crítica de arte al publicar "Para iniciar una sección de crítica de arte", una especie de breve estudio-manifiesto con el cual expone la preferencia hacia el arte abstracto y teoriza sobre los estilos dominantes en la historia de la pintura, aportando una lectura que los exime de consideraciones uniformes o monolíticas.

"A las palabras les daremos la responsabilidad de su significado preciso; así no esquivaremos el dificultoso problema crítico que impone el arte en este período de continua e inteligente inquietud (...).

Nuestras convicciones sobre la pintura abstracta, sostenida por el orden geométrico, no tienen pretensión de detener o desconocer la evolución de las artes figurativas, que podrá reservarnos todavía sorpresas; así como esas mismas convicciones que pueden permitirnos admirar y comprender las corrientes de la intuición creadora de Picasso y Klee”. ${ }^{26}$

A lo largo de sus primeros artículos, explicita sus consideraciones sobre la historia del arte como una serie de eventos internos y externos a la cultura visual que inciden en la creación de nuevas formas, las cuales buscan su evolución a través de un orden geométrico claro. En este trayecto de reconstrucción de estilos, modos y gustos, la sensibilidad de Rossi también sobresale por sus conocimientos prácticos. Algunos de sus trabajos más memorables en este ámbito, son las tapas de la ya mencionada revista milanés Campo Grafico, creada en 1933 junto a Dradi y el icónico diseño del libro Kn de Carlo Belli, con una célebre cubierta que da coherencia a los elementos gráficos, visuales y de contenido, afrontando con originalidad en $1935^{27}$ argumentos que actualmente se relacionan con el estudio de la "identidad gráfica" de los productos. En sus obras, Rossi se adelanta a su época y revela una sutil afinidad hacia lo esencial del diseño.

\footnotetext{
${ }^{25}$ BENJAMIN, Walter: La obra de arte en la época de su reproductibilidad técnica, México D.F, Itaca, 2003.

${ }^{26}$ ROSSI, Attilio: "Para iniciar una sección de crítica de arte", Sur, n. 16 (enero 1936), p. 83.

${ }^{27}$ ROSSI, Pablo: Alla scoperta delle «Lettere perdute» di Attilio Rossi, Milán, Ed. Privata, 2012.
} 
Afianzado en Sur, escribe y se interesa tanto por las artes plásticas, como por el cine, la arquitectura contemporánea y la organización de las exposiciones. En una cultura que busca su propia identidad, él encuentra la suya. En su rúbrica, se puede reconstruir una finalidad didáctica coherente con el proyecto de la revista; se trata de innovar el modo de pensar el arte más que enseñar a reproducirlo. La idea es la de difundir una posición que se replantee el sentido crítico del pensamiento artístico y que vaya más allá de la discusión sobre las reglas de la composición cromática. En poco tiempo, las ideas Rossi revolucionarán la figura misma del crítico de arte y sus textos conformarán una bitácora hacia el lenguaje contemporáneo del arte argentino, al mismo tiempo que consolida su identidad como portavoz internacional del arte moderno.

En los años siguientes, Rossi seguirá desempeñando un papel importante respecto a la relación entre el discurso crítico y la producción artística local que, paulatinamente se irán superponiendo. Por ejemplo, en 1937 se inaugura la Primera exposición de dibujos y grabados abstractos en la Galería Moody, en la cual Rossi es el curador y el crítico de su misma exposición. Este acto, que lo pone en un rol polivalente, demuestra un cambio en la impronta de sus estrategias a medida que avanza la estructura de su discurso crítico. La exposición presenta un panorama actual de las artes plásticas italianas que ostenta su red de contactos con artistas de "hibridación peninsular", es decir pintores y escultores formados o erradicados en Italia pero con orígenes argentinos. Rossi enfatiza el tema del intercambio entre artistas e imagina en la posible "compatibilidad cultural", el elemento de transmisión de los conocimientos aprehendidos.

Confirmándose como conocedor del escenario internacional, Rossi permanentemente señala (y de manera implacable) la pobreza conceptual de muchos de los artistas más estimados del panorama argentino, no solo desde las páginas de la revista, sino también desde los salones expositivos.

"Los dibujos en blanco y negro y los dibujos coloreados que expone la señora Forner no llegan, ni con la ayuda de la curiosidad documental, a atenuar esos defectos ni a superar con el interés pictórico la monotonía del tipo de rostro escogido como expresión humana de los lugares visitados. Demasiado acabados para ser impresiones de álbum de viaje; demasiado incompletos para ser cuadros". 28

Rossi pasa de narrador a protagonista. Su compromiso en la construcción de un gusto moderno y porteño, lo confronta con las relaciones privilegiadas implícitas en las "buenas costumbres" de los críticos "institucionales" respecto a los artistas nacionales. Sus textos

${ }^{28}$ ROSSI, Attilio: “Raquel Forner en la Galería Müller”, Sur, n. 22 (julio 1936), p. 87. 
muchas veces llegan a tocar la insolencia, en el mejor estilo militante, contestando objetivamente las actitudes de los salones expositivos, de los otros críticos de arte y especialmente la producción de algunos pintores locales, como en el caso de la pintora Raquel Forner $^{29}$. El carácter directo de Rossi cuando se ocupa de la cultura visual y de la teoría del arte, pone en evidencia la falta de formación local en el panorama contemporáneo y su tono reactivo hace que sea difícil percibir en su propuesta una actitud reflexiva y de "crítica activa". Estas incomprensiones del ambiente, generan varias protestas a su columna por parte de los críticos más afianzados con el gusto institucional y que prefieren las reminiscencias del arte figurativo. La Buenos Aires de este período se encontrará en una encrucijada marcada por la intersección de lo moderno y lo tradicional.

A partir del número 20, Rossi determina su propuesta como crítico: define su línea de pensamiento e indica las limitaciones específicas del contexto argentino cuyo gusto, ante la falta de tradición y la excesiva interferencia política, es el reflejo de la clase aristocrática conservadora que, plenamente institucionalizada, determina el lenguaje de los artistas.

Dadas las circunstancias, el compromiso de Rossi se centrará en el aspecto estético y en el debate creativo sobre la construcción de una obra de arte alternando diferentes puntos de vista, por un lado tratando de crear un vocabulario específico para abordar visualmente el "evento" artístico, se trate de una pintura, una muestra, etc., dado que el valor estético está en la integridad de la expresión formal. Por el otro lado, Rossi trata de disociarse del contexto académico y busca enfatizar las características de una composición que debería orientarse hacia una estética contemporánea determinada por el orden geométrico y por la exploración de las formas ajenas a la naturaleza.

A lo largo de sus textos, se declara consciente de la situación contingente del arte en Europa y en particular de la coyuntura argentina. Dentro de Sur y con gran habilidad en el campo de las artes plásticas, Rossi introduce las obras que, según su punto de vista, tienen valor estético así como los trabajos de algunos artistas con los cuales comparte una afinidad italianizante, como en el caso de Emilio Pettorutti ${ }^{30}$ y Lucio Fontana ${ }^{31}$. Las obras de estos

29 "Forner había sido premiada en dos ocasiones en los salones nacionales; expuso en Estados Unidos y anteriormente, en París, donde además estudió con Othon Friesz y a su regreso a Argentina, participó en el Salón de los Pintores Modernos (Buenos Aires, 1931), junto a Alfredo Guttero, Pedro Domínguez Neira y Alfredo Bigatti"; SUÁREZ GUERRINI, Florencia: op. cit.

30 "Una exposición de Pettorutti es un acontecimiento notable en la pintura argentina. Es aguardada con desprecio por la gran muralla construida por la pereza mental, con reserva por las personas vacilantes y con gozo por toda la gente que ama el arte noblemente, sin preconceptos. La personalidad artística de Emilio Pettoruti impone respeto (...). La pintura de Pettorutti como, por otra parte, toda la pintura moderna, desprovista aun de la sugestión histórica, hay que amarla intensamente, noblemente."; ROSSI, Attilio: "Emilio Pettoruti en la Galerìa Nordiska", Sur, n. 25 (octubre 1936), p. 95.

31 Rossi había intentado introducir a Lucio Fontana en el ambiente artístico argentino, trabajando juntos para 
artistas se deslizan entre contradicciones e incertidumbres pero con la intención de generar nuevos debates y modelos, que conviven no necesariamente sin conflicto con las posiciones más académicas y tradicionalistas en relación a los aspectos mencionados. Al enfatizar sus preferencias y al excluir algunos artistas por contraposición, Rossi hace evidente la actitud negligente de las instituciones culturales que determinan los cánones del arte mediante presupuestos no objetivos.

\section{Sobre la crítica y la desterritorialización del arte}

La organización de los textos de Rossi revela claramente los objetivos fijados a favor de la "modernización" cultural para Buenos Aires, período en el cual surgen grandes tensiones entre la tarea del intelectual como la entendía Sur y el contexto local. A este punto, la revista se propone como espacio de diálogo entre opiniones discordantes. Por éste motivo, Surse abre al debate y publica en 1937 un texto escrito por Mallea que trata de contextualizar las ideas de Rossi y la posición de Sur respecto a las cuestiones culturales.

"Estábamos haciendo Sur. Sur, es una revista de minoría, por lo tanto, una revista de solitarios. Una revista de descontentos, una revista del querer hacer y ser mejor. Y Rossi vino a trabajar con nosotros y pensamos que nuestro arte, nuestra pintura reciente, necesitaba de un hombre con un fuego no de llanura, como el nuestro, sino de entraña como el de Rossi, italiano, hombre joven de la tierra del Giotto y también de la tierra de Modigliani. Con una madurez diferente a la nuestra y fertilidad verde, nuestra fertilidad en agraz. Un hombre que viniera con nosotros, haciendo, por ánimo cordial, de nuevo, un camino que ya había hecho en la ruta del arte italiano.

Y Rossi ha incorporado a la maduración del arte argentino su amistad madura, su inteligencia vehemente, su sabiduría, su tenacidad de trabajador alucinado. Y no solo ha hecho crítica de nuestra plástica, sino crítica de cinematógrafo, crítica de ese arte que tiene la edad americana, y ha traído, además, como si todo eso fuera poco, la artesanía de un admirable artista gráfico.

Por hombres como éste se honra en tierras extrañas la inteligencia original, natural de un país. Por hombres como éste se piensa con esperanza y gozo en la posibilidad naciente de un mundo nuevo, de un mundo -por fortuna- diferente a otro que acaba. Por hombres como éste, este Attilio Rossi, sabemos unos cuantos argentinos -y no tal vez los que menos importan- lo que es la inteligencia de un admirable italiano cuando en la levadura de esa inteligencia se levantan, auténticos, una voluntad, un sentido, una libertad, una intrepidez, una lucidez y aquel obstinado rigor que destinaba para su método Leonardo.” 32

un concurso en Buenos Aires durante 1936. Fontana, había nacido en Argentina de padres italianos. Originario de la provincia de Santa Fé, no pertenecía al círculo intelectual de Buenos Aires. Por deseos del padre, creció y estudió en Italia. Rossi intenta construir una cercanía hacia Italia para los argentinos desde los mismos argentinos «híbridos». La amistad entre ambos artistas se remonta a la publicación de la monografía sobre Fontana publicada por Campo Grafico, realizada por Edoardo Persico y editada por el mismo Rossi.

32 MALLEA, Eduardo: “Rossi en Buenos Aires”, Sur, n. 30 (marzo 1937), p. 118. 
Con esta cita, extensa pero necesaria, sin hacer comentario alguno acerca de los incómodos protagonistas ${ }^{33}$, Mallea cerraba el campo polémico que se había establecido en torno a Rossi. Por consiguiente, le concede el dominio de la escena artística casi por completo, exaltando tanto sus orígenes como su formación, atribuyéndole capacidades decisivas para reconocer el mérito estético de las obras. Los lazos dentro del campo artístico progresivamente se volvieron más estrechos y así, el crítico de arte en virtud de su posición, tenía la responsabilidad de emitir opiniones e ideas en función de que el público pudiera ser "orientado" en los términos específicos del campo creativo. Sin embargo, algunos críticos locales no coincidían ni con la actitud de Rossi ni con la de la revista frente a las producciones locales. Dicha incomprensión se debe a la incapacidad de percibir que la crítica misma de Rossi es también un gesto creativo dentro del trasfondo histórico y cultural; un gesto que se propuso simultáneamente formar el gusto del público y establecer las bases de una crítica del arte activa en Argentina.

Volviendo al texto de Mallea, su relevancia radica en el carácter testimonial respecto al contraste de opiniones entre los que detentaban el control en el ámbito del gusto. Este texto también señala que el proceso que se instaló durante la búsqueda de la modernidad estuvo cargado de tensiones y contradicciones dentro de un mismo espacio, como lo fue Sur, si se piensa en el debate entre Rossi y Marechal ${ }^{34}$.

Al margen de las polémicas, para Rossi la crítica de arte es un factor fundamental del campo artístico como propuesta formativa. Es importante destacar que tanto Sur como su crítico, tienen una identidad bien precisa y una convicción respecto a la naturaleza pedagógica de la crítica de arte. En el caso de la revista, la propuesta editorial coincide directamente con la gestación de la identidad lingüística argentina, que surge de la expresa voluntad de Victoria Ocampo de traducir en el país todos los textos de escritores europeos y norteamericanos que serán publicados ${ }^{35}$, tanto en la revista como en la editorial, con el propósito de no excluir los lectores monolingües. Contemporáneamente, con esta decisión se pretende difundir, y de alguna manera unificar, una línea de pensadores comunes para Latinoamérica. La relevancia de la revista de Ocampo esta dada por el modo con el cual pretende establecerse como un

\footnotetext{
33 Consagrados críticos de arte argentino como Julio Rinaldini, vinculado al grupo del diario La Nación y portador de una crítica de arte más tradicional, asi como Leopoldo Marechal, también colaborador de Sur como crítico de arte, contestan las opiniones de Rossi en dos artículos: "Experiencia de una exposición de arte", en Sur, n. 22 y "Carta abierta" en Sur, n. 25, respectivamente.

34 Entre el número 25 y el 29 de Sur del 1936 hay un encendido intercambio de opiniones respecto a la actitud militante de Rossi. Otros representantes del gusto local (como Leopoldo Marechal y Julio Rinaldini) que se ocupaban de la crítica de arte, toleran poco (y lo hacen público) la actitud del "huésped" italiano.

35 Por ejemplo, Victoria Ocampo se ocupó personalmente de traducir todos los ensayos y novelas de Virginia Woolf, así como las obras de T.E. Lawrence para el lector hispanoparlante.
} 
punto de referencia cultural, que puede orientarse a reforzar distintos campos de estudio, es decir ampliar tanto el ámbito artístico como en campo literario, sociológico o de la mediación cultural, porque la revista también trata de forjar los nexos de una identidad americana a partir de temas compartidos. En el caso de Rossi, la cuestión de la identidad es mucho más determinante; es una cuestión que lo lleva a desarraigarse de su propio país a partir de sus fuertes convicciones respecto a temas políticos así como respecto al lugar y a la función del $\operatorname{arte}^{36}$. Su presencia, ayuda a comprender el vínculo de Victoria Ocampo con el mundo intelectual, y luego, la intencionalidad detrás de una identidad característica que determina ciertas elecciones, siendo el multiculturalismo también un acto de afirmación del pensamiento moderno.

Es en este entorno donde los primeros artículos de Rossi tratan de regular la crítica de arte con el objetivo de relacionar el clima artístico e intelectual argentino, con el panorama europeo. Sin embargo, también una de sus principales tendencias será tender un puente entre la crítica de arte y la cultura italiana, entre la crítica de los clásicos y las producciones contemporáneas, alejándose de la lectura histórica y proponiendo una interpretación más natural del objeto. Con Rossi, el arte viaja en su forma política, mediante un discurso lógico y retórico que establece la capacidad de discernimiento en cuanta posibilidad de cuestionar la hegemonía iconográfica.

Desde su vocación de enseñar a pensar el arte más que a reproducirlo, Rossi se posiciona en el acto analítico del discurso, abandonando la descripción literaria. El incentivo a abordar visualmente la obra desde la empatía, permite descubrir la gramática intrínseca en la relación de los elementos plásticos que buscan crear un vocabulario específico: el del arte moderno. Los orígenes italianos de Rossi, así como la fuerte presencia de inmigrantes connacionales, lo ponen en una posición privilegiada como mediador porque reconstruye naturalmente el vínculo con una gran cantidad de artistas que él mismo frecuentaba en Milán. Se trata entonces de un encuentro italo-argentino que ya no es parte de la lógica del conocimiento, sino de una estrategia de mediación para consolidar conceptos y ampliar el sistema de referencias del público y de colegas en el nuevo universo del arte moderno.

\footnotetext{
36 A dos años de fundar Campo Grafico, Rossi deja Milán debido al profundo malestar político e ideológico ante el fascismo italiano. A los márgenes del Río de la Plata, surge la posibilidad de desarrollar un proyecto gráfico y editorial similar al de 1933, pero esta vez con Gino Fogli. Ya en Buenos Aires, Rossi conoce personalmente al escritor argentino Eduardo Mallea. Precedentemente, Mallea junto con Victoria Ocampo, habían viajado a Italia para promocionar la producción cultural argentina, invitados por el Ministerio de Cultura y Relaciones Exteriores italiano. Durante este viaje, tendrán una serie de conferencias en Florencia, Venecia, Roma y Milán. En esta última ciudad, Mallea encuentra al escenógrafo Cesare Zavattini, que será el trait d'union entre Sur y Attilio Rossi
} 
Son algo más de veinte los ensayos que Attilio Rossi escribió en Sur. Textos dedicados a las artes plásticas, o que tratan de cine o de arquitectura, constituyen un documento clave que confirma los objetivos de un proyecto de renovación estético-cultural que abarca el universo completo del arte. Sus textos incluyen reflexiones hacia artistas, así como críticas sobre el sistema oficial del arte local y hacia las propuestas expositivas. Desde su trabajo como crítico, modera la controversia y la reflexión, mientras interpreta y relata los eventos, se aleja de una simple figura de intérprete. El mismo Rossi escribió:

“También 1937 pasó sin que en las artes plásticas argentinas se definiera una justa autoridad en favor de los valores auténticos (...) Intervenir, discutir, criticar es acto de virilidad que, cuando está apoyado de inteligencia, siempre puede hacer brotar una idea. Y una idea ponderada, discutida, ampliada por personas capaces y optimistas puede llegar a romper la rutina que es tan perjudicial como cómoda de aceptar". ${ }^{37}$

El arte de provocar al lector es para Rossi un camino de reflexión sobre el estado mismo del arte, la crítica es un argumento lógico que, evocando la historia se declina en un arte en sí mismo que implica una emancipación del canon y del condicionamiento cultural; no se trata de un medio para proponer teorías abstractas referidas a la pintura, el cine o la arquitectura; se trata de una visión global y analítica que rescata la armonía estética entre la composición de sus elementos de acuerdo a su tiempo.

"El factor negativo local, al que antes me referí, sumado a la reacción de la clase burguesa, turbada en todo el mundo por la verdades de las vanguardias, desvía corrientes vitales de la actividad de artistas jóvenes (en nuestro caso la sección de artes plásticas de la AIAPE) llevándolas a defender la libertad de la cultura con las armas plásticas, en vez de servirse solamente de armas organizadoras, con pleno daño del arte y de su intrínseca esencia revolucionaria". 38

Rossi sugiere que de alguna manera (incluso si no lo explica claramente) los artistas argentinos más consagrados, lo deben a la sensibilidad negligente de los críticos locales y es esto lo que no permite la verdadera renovación de las artes En su polifacético rol de artista erudito y crítico militante, sus artículos sobre las exposiciones podrían entenderse como el comienzo de una forma de comisariado. Nuevamente, Rossi pone en juego su competencia como diseñador gráfico que se traduce en una actividad visual que busca continuamente el equilibrio entre los elementos de la obra, pero también en la secuencia expositiva de una muestra que compone la totalidad del evento. La cuestión se hace explícita cuando se publica

${ }^{37}$ ROSSI, Attilio: "Una idea”, Sur, n. 40 (febrero 1938), p. 83.

${ }^{38}$ ROSSI, Attilio: "Para iniciar una sección de crítica de arte", Sur, n. 18 (marzo 1936), p. 84. 
el número 28 de Sur (1937) "Primera exposición de dibujos y grabados abstractos en la Galería Moody":

"Las finalidades de esta exposición, puramente ideales han sido explicadas por nosotros en la invitación (catálogo junto con una declaración de invitación) catálogo de los expositores y una pequeña biografía de cada artista con el fin de orientar al público sobre la seria autenticidad de los trabajos que se exponen". ${ }^{39}$

La voluntad de producir una ruptura con las condiciones del panorama local, en este caso lleva a Rossi a ocupar un rol ambivalente al ser el crítico de arte de su propia exposición. Como curador de la muestra, analiza las opiniones publicadas sobre la exposición que él mismo ha organizado y comenta con un tono particularmente positivo las cualidades favorables del evento:

"Es esta una exposición organizada por nosotros pero eso no nos impide hablar a nosotros mismos sobre ella porque no queremos, con estas líneas, ostentar «vanagloria» sino solo registrar el feliz éxito de la exposición y sus repercusiones satisfactorias en un cierto sector de la juventud que, por fortuna, no se saludan aún con el good-bye aprendido en el cinematógrafo". 40

La lista de los participantes italianos en la exposición es una muestra significativa del debate cultural sobre la cuestión moderna. El rol ambivalente de Rossi es, sin duda, una audacia cuestionable pero en línea con una provocación creativa y una forma de reafirmar su autoría. La exposición es el resultado de una iniciativa personal que comienza en octubre de 1936, cuando reanuda una serie de contactos con artistas afines. Si se quiere, no es casual que Emilio Pettoruti (participante a la muestra) precediera a Rossi en Sur con un artículo titulado "Fines y organizaciones de los salones de arte" en 1935". La crítica, por lo tanto, es entendida como un ejercicio de comisariado; un medio para orientar nuevas teorías de gusto y la curiosidad del público. Volviendo a Rossi, la reseña sobre la "Primera exposición de dibujos y grabados abstractos", es una de las pocas notas que se publica con imágenes. El exceso de racionalidad que contenía, trata de poner en evidencia que las buenas intenciones tienen valor solo cuando se traducen en un objeto, es decir un ejemplo que constata las ideas implícitas en sus textos y que, en esta ocasión, afirma la coherencia entre el lenguaje del arte y la funcionalidad expositiva. Por tal motivo, un papel importante lo juega el recorrido, que

${ }^{39}$ ROSSI, Attilio: "Primera exposición de dibujos y grabados abstractos en la Gallería Moody", Sur, n. 28 (enero 1937), p. 94.

40 Ibídem: pp. 92-98.

${ }^{41}$ PETTORUTI, Emilio: "Fines y organizaciones de los salones de arte", Sur, n. 12 (septiembre 2013), pp. $92-97$. 
orienta al público espacial y conceptualmente a favor del arte abstracto. Para enfatizar el rigor implícito en la organización de "su" exposición y con el objetivo de contextualizar las obras, se crea la "vitrina polémica"; un salottino articulado en torno a libros, revistas e imágenes que sirven para dar al público la posibilidad de exhaurir sus inquietudes, manteniendo la esencia didáctica de la práctica crítica. Entre las obras seleccionadas, se encuentran los trabajos de los artistas argentinos Juan Bay y Lucio Fontana, residentes en Milán, junto con los italianos Ezio D’Errico, Fausto Melotti, Mario Radice, Mauro Reggiani, Atanasio Soldati y Luigi Veronesi. En su artículo, si bien Rossi no aclara el significado de las obras seleccionadas ni se refiere al componente unilateral italiano, hace explícitas algunas de sus ideas más personales, incluida la relación creativa que algunos artistas establecen con los materiales no convencionales y teoriza, como en el caso de Fontana, que esta relación responde a componentes instintivos o intrínsecos en la naturaleza noble de los mismos.

"Carmelo Arden Quin, Tomás Maldonado, Gyula Kosice, Lidy Prati, Enio Iommi, Juan Melé, Blaszko, Rothfuss, Hlito y Lozza, entre otros, forzaron los límites de la abstracción, iniciada en nuestro país por Pettoruti, Del Prete y Fontana, para dar paso al Arte Concreto Invención-Arte Madí, movimiento originalísimo que toda- vía hoy despierta un interés inusual entre curadores y coleccionistas internacionales". ${ }^{42}$

El aspecto más relevante de la muestra (y del artículo) es la declaración implícita de la centralidad italiana en el desarrollo del arte moderno. Rossi tiene la oportunidad (y la aprovecha) de confrontar dos contextos artísticos y culturales al proponer, en tiempo casi real, las tendencias europeas más innovadoras a un grupo de artistas e intelectuales. Pero más que la confrontación real de tendencias de un contexto a otro, la contraposición entre el arte local y el italiano, se convierte en una metáfora de la desprovincialización y modernización de la cultura en general. Es quizás aquí donde el papel de Rossi se hace más claro. Por consiguiente, en la parte final del artículo, se da al lector un informe detallado del clima artístico argentino y se revela la complejidad que implica la evolución del arte.

"Nuestra posición explicada pedantemente en todas las ocasiones que se nos han presentado y en estas mismas páginas y nuestra línea de conducta en defensa del núcleo de artistas modernos que han tenido sus fases más importantes en la batalla contra el silencio y los débiles consejos engañosos, puestos como diques, contra la influencia de las exposiciones de Pettoruti y Del Prete nos ha servido a dar también a esta exposición un carácter definido, es decir solo hostil para la ignorancia presuntuosa". ${ }^{43}$

42 DE ARTEAGA, Alicia: “El otro sueño americano”, La Nación, [consultado: octubre 2017]

Disponible en http: www.lanacion.com.ar/cultura/el-otro-sueno-americano-nid467286/

43 ROSSI, Attilio: "Primera exposición de dibujos y grabados abstractos en la Gallería Moody", Sur, n. 28 (enero 1937), p. 97. 
Con esta frase, Rossi responde a quién le reprochaba una actitud mordaz y demuestra que su dominio de la escena artística es casi integral, tanto desde la teoría como desde la práctica.

\section{Consideraciones finales}

En este punto es evidente que las experiencias de mediación cultural son parte integral de la trayectoria biográfica e intelectual de la actividad creativa de Attilio Rossi. Tanto en su correspondencia como en sus más variados trabajos, hay indicios que atestiguan que su obra está guiada por la necesidad de actualización y confronto interdisciplinario, como lo muestra el énfasis con el cual se dedicó a la pintura, a redactar artículos de inédito respiro crítico y a organizar exposiciones involucrando artistas de prestigio internacional.

Gran conocedor del escenario práctico y teórico, su perspicacia lo convierte en uno de los grandes impulsores de la innovación en la cultura visual en ambas partes del Atlántico. En las páginas de Sur queda demostrado que su actividad teórica le dio la oportunidad de hacer de sus ensayos una herramienta de renovación de las artes visuales.

Promover una comprensión más completa de sus textos, permite ordenarlos desde una perspectiva que introduce criterios modernos en la práctica de una disciplina que se estaba configurando. Considerando estas circunstancias, este texto completa algunos aspectos de la personalidad Rossi enfatizando el legado intelectual que introdujo en Buenos Aires y que, con sus aportes en la formación del sistema de arte contemporáneo argentino, ayudó a abrir el camino de la crítica especializada como una profesión independiente del ambiente literario. Su innovación reside en entender la crítica de arte como un ejercicio de teorización del gusto; un arte en sí mismo que viaja en dos direcciones resignificándose en el trasfondo histórico y cultural de una ciudad que dio origen a las manifestaciones más relevantes de la cultura argentina durante este período.

El legado intelectual que deja Rossi en Buenos Aires ha contribuido decisivamente a difundir, especialmente en el público, la crítica de arte como una verdadera disciplina y como una forma de interpretación activa, militante, que considera la esencia del arte como una práctica analítica constante y como un espejo de su tiempo. 